PINK RIBBON AND PINKTOBER

\title{
Dr. Sofia Shehzad
}

The month of October comes with a familiar sight of 'pink ribbon' display and events organized in this context, globally. While this is an integral part of the international calendar in the developed world, developing countries like Pakistan attach little importance to promotion of this concept brand. One of the reasons for this apathy is a lack understanding amongst the social circles and general population about what the pink ribbon advocates. This editorial is meant to highlight the true spirit and importance of this symbol.

A 'pink ribbon' is an international symbol of breast cancer awareness with the month of October referred to as 'pinktober' chosen as the breast cancer awareness month in many countries over the world. Breast cancer is the most common cancer amongst the female gender with more than one million women worldwide diagnosed with the disease every year. The WHO in its global health estimate reported 508000 deaths in women worldwide from this disease in the year $2011^{1}$. More than $58 \%$ of deaths from breast cancer are known to occur in less developed countries ${ }^{2}$, which sets aside the misconception that the disease is a problem of the more affluent class. Early detection of breast cancer with its favorable impact on morbidity and mortality associated with the disease is now established as the cornerstone of management ${ }^{3}$.

Against the backdrop of the magnitude and impact of this condition there is a dire need for creating awareness about the symptoms and treatment of the disease as well as promoting research and facilities leading to early detection, multimodality treatment and support for those suffering from the disease. Pink ribbon as a concept brand allows a platform to achieve these goals by raising money and encouraging scientific progress. The first known use of Pink Ribbon dates back to 1991 when it was handed out by the Susan G Koman foundation to participants of a New York city race for breast cancer survivors and adopted as an official symbol in $1992^{4}$. Buying, wearing, displaying or sponsoring pink ribbon is a sign of support for women health. Thousands of pink ribbon products are advertised and sold each year with part of the earnings spent in promoting breast cancer awareness and funding research.

The month of October as the national breast cancer awareness month (NBCAM) was started in 1985 by the American Cancer Society and pharmaceutical company Astra Zeneca. The organization behind NBCAM is keen on promoting mammography as a screening tool for early detection of breast cancer. Running, walking and riding besides observing pink dress day and pink hijab day form the essence of events organized globally as fundraisers under this banner.

The campaign for helping breast cancer patients is not limited to diagnosis and treatment only. Addressing the burden of physical, social and psychological stigma associated with the disease is as important as the initial steps in management. The term She-ro, derived from hero is sometimes used to refer to those suffering from the disease. After treatment, the she-ro regains her femininity by using breast reconstruction, prosthetic devices, wigs, cosmetics, and clothing to present an aesthetically appealingappearance ${ }^{5}$. Breast cancer culture, or pink ribbon culture, refers to steps taken in public to effectively address different aspects of the disease. It supports the efforts of the doctors, promotes diagnostic modalities such as mammograms and various treatment options on offer for breast cancer patients. 
Pakistan has the highest rate of breast cancer in Asia. One out of every nine women is at the risk of breast cancer making the Pakistani women most susceptible to the disease after the non Arab Israeli women ${ }^{6}$. Studies have shown that a significant number of young women make the aforementioned list. Therefore, Pink Ribbon has reading-prc-Iterature been running Youth Awareness Program in collaboration with Higher Education Commission (HEC) since 2012. This program not only educates the young women about the importance of self-examination and screening modalities like ultrasound scan and mammograms but also through their interaction with members of their family and society makes them conscious of the disease and advocating regular check-ups. Benefit is also derived from established women groups and Lady Health workers who are in contact with the population in far-flung areas of the country, in spreading awareness to the grass root level. In collaboration with Pakistan Atomic Energy Commission hospitals, Pink ribbon has launched a free nationwide Breast Cancer screening program and is working on building a dedicated Breast Cancer Hospital in Lahore, Pakistan.

Realizing the disease burden and the health, social and financial implications of breast cancer it is imperative that Pink Ribbon as a source of Breast Cancer awareness is propagated in the society and an all out moral and material support be extended to the organizations working under this banner.

\section{REFERENCES}

1) The WHO Global Health estimates,(2013)www.who.int/cancer/detection/ .../en/index1.html

2) GLOBOCAN 2008. http://globocan.iarc.fr

3) Anderson BO, Yip $\mathrm{CH}$, Smith RA . Guideline implementation for breast healthcare in low income and middle income countries, Cancer 2008 Oct 15; 113(8suppl)): 2211-43

4) Gayle A. Sulik. Pink Ribbon Blues: How Breast Cancer Culture Undermines Women's Health. USA: Oxford University Press. pp. 47-48.

5) Sulik, Gayle (2010). Pink Ribbon Blues: How Breast Cancer Culture Undermines Women's Health. New York: Oxford University Press. ISBN 0-19-974045-3.

6) Liede A, Malik IA, Aziz Z, et al (2002). Contribution of BRCA1 and BRCA2 mutations to breast and ovarian cancer in Pakistan. Am J Hum Genet, 71, 595-606.
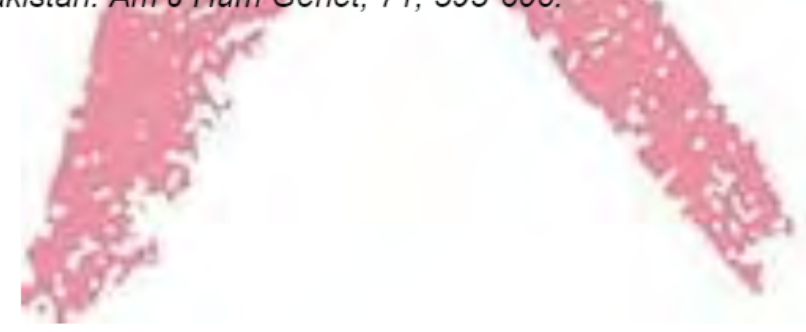
LICENSE: JGMDS publishes its articles under a Creative Commons Attribution Non-Commercial Share-Alike license (CC-BY-NC-SA 4.0).
COPYRIGHTS: Authors retain the rights without any restrictions to freely download, print, share and disseminate the article for any lawful purpose. It includes scholarly networks such as Research Gate, Google Scholar, LinkedIn, Academia.edu, Twitter, and other academic or professional networking sites 